\title{
THE SMART TEXTILE PROBLEM AND ITS IMPLICATION FOR TEACHING
}

\author{
L. Tandler \\ Royal College of Art (UNITED KINGDOM)
}

\begin{abstract}
The $21^{\text {st }}$ century has seen the textiles industry and academy face the challenge of smart textiles. There is a popular view that describes smartness in textiles as a synonym for responsive behaviour. This perception however is challenged by the idea that all natural textile materials change in reaction to its environment. A question therefore remains as to what responsive behaviour constitutes as smart behaviour. In other words, when does the responsive turn into smart?
\end{abstract}

The textile industry heavily relies on weaving as the construction methodology for cloths. Weaving, and woven materials, have changed very little since the Stone Age. Even the Industrial Revolution only changed the speed and efficiency of weaving - but not the basic structure of woven materials themselves. The dramatic change that was introduced from the Industrial Revolution is the bonded dependency of structures potentials in the specifications of the machines. This link still rule textile manufacture today and the interesting thing here is that our weaving machines have only changed a little in over 250 years.

The dramatic introduction and ever increasing development of new technologies and textile components has created, as a result, an inherent gap between cutting edge technologies, advanced material science and what could only be described as ancient textiles construction methodologies.

This session will outline the issues concerning smart textiles. It will portray the weaver as a behaviourist learner and will introduce the formation of a new experimental learning space through a plantation of a rhizomatic strategy within a behaviourist discipline. The session will consequently discuss why such seemingly two incommensurable approaches to learning - behaviorism and rhizomatism - may come together and work alongside one another through a new agonistic and interdisciplinary space to allow the development of innovative textile structures.

This session will appeal to textiles designers, makers, teachers and researchers from all creative disciplines. It will also appeal to those interested in pedagogic frameworks and research into academic structures and delivery of programs.

Keywords: Weaving, smart textiles, behaviorism, rhizomatism, pedagogy, learning strategy, experimental workshop, construction methods.

\section{INTRODUCTION}

The 20th century saw the dramatic introduction of STEM (Science, Technology, Engineering and Mathematics) to the production of textiles - particularly with the development and manufacture of manmade fibres and yarns following the breakthrough discovery of polymer science. Indeed the addition of manmade materials into the textile industry has proven transformative and provided the ability to control the properties of textiles themselves [1], [2], [3], [4]. Since then, manmade fibre production has been at the forefront of innovation with various fibre materials and yarns emerging onto the market to suit specific textile applications [5], [6], [7], [8], [9], [10]. And while no one material is likely to fulfil the requirements of all potential applications, the high costs that are involved in the research, development and production of such tailor-made fibres is now understood to not be sustainable in the long run [11]. As a result much attention has been diverted onto the development of hard technologies with an ambition to create textiles of phenomenal qualities and performances. Those fibres, yarns and technological innovations have formed the back bone of three major areas of research: electronic textiles, technical textiles and smart textiles. 
Electronic textiles - the veterans of the three - are those that simply conduct electricity [12] and although many designers and researchers have attempted at them since the 1990s, they are hardly a new research interest, with considerable attention being given to them back in the early part of the 20th century [13]. Technical textiles are those aimed at fulfilling specific functions [14]. These, often rely on fibre and yarn developments as well as various coating applications to enhance their performance [15]. Smart textiles are a little more ambiguous. Although smart textiles are often discussed across academia - as well as within the public domain - the definitions that seek to explain their unique benefits and value are often contradictory and lacking in coherence.

This leaves us - as practitioners and as teachers - with a problem. And this problem has two faces. The one relates to understating the aims of smart textiles and therefore understanding how we are to create them. And the second, similarly, relates to choosing the appropriate methods for teaching and transferring that knowledge onwards though theory and practice. In this paper therefore, I will look at the sort of teaching and research that might be necessary in order to prepare the ground for a genuine breakthrough in the creation of truly smart material systems.

\section{METHODOLOGY}

The findings of this paper are the product of three years of investigative inquiry into the meaning of smart textiles. The research itself looked at the phenomena of smart with a critical eye in an attempt to demystify much of the ambiguity that has been associated with it in recent years [16]. This paper summaries some of these findings through practice and theory with an emphasis on teaching. This paper uses weaving as a case study - examining our long evolved methods of teaching and learning and reevaluating those in light of the new knowledge that emerged from the research into smart textiles, and particularly the evolving role of weaving in the creation of smart textiles.

\section{RESULTS}

Smart textiles are a relative new invention and have been around since around 2000 [6]. The first meaningful attempt at describing smart textiles comes from Tao (2001), who classified textiles according to their level of smartness. In Smart Fibres, Fabrics and Clothing: Fundamentals and Applications, she describes smart materials as those that sense and react to environmental conditions or stimuli, where these - very crucially - are then further classified into passive smart, active smart and very smart [17]. To this day, this academic definition remains one of the only critical attempts at describing the nature of smart in relation to textiles. Subsequent attempts to simplify Tao's descriptions of smart textiles have resulted in misleading interpretations of smart behaviour in textiles. For instance, it is now widely believed that smart textiles are those textiles that are susceptible to changes in the environment, such as moisture, temperature, light, electrical current and/or chemical stimulation [18], [19], [14]. The problem with such a definition, however, is that to some extent every piece of textile changes in reaction to its environment [20], [10]. It has been long understood that it is those precise changes in the environment that would allow cotton, for example, to shrink [21] and wool to retain moisture [22]. A question therefore remains about the difference between merely responsive behaviour and genuinely smart behaviour [16]. In other words, when does the responsive turn into the smart?

\subsection{The challenge of smart textiles}

There has been much debate amongst STEM practitioners who sought to understand the merits of genuinely smart materials [23], [24], [25], [26]. The issue at hand is not the lack of understanding of the term smart across STEM, but rather the lack of this understanding among designers, who are key participants in the introduction of new textile materials into the marketplace. And this had become particularly evident in the past 20 years when textiles designers have attempted at implementing foreign hard technologies into textiles in the hope that this would transform them into smart. Indeed it is today a common practice across academic institutions to educate their design students that the merits of smart textiles are solely dependant on the properties of individual components that are to be fitted onto or into the textile. In those cases, the technology is separate to the textile and as a result the material system itself is ignored. The problem here is that the textile itself is insignificant with the smart behaviour deriving solely from the hard technologies - often developed far and removed from the textile itself [12]. This has muddled our understanding of smart, transforming the technical, electronic and smart textiles to synonyms of the same obscure meaning. 
A common misperception begins when textiles are referred to as materials - whereas, in fact, textiles are better understood as material systems [16]. The particular hierarchical structure of textiles attributes them with unique performance possibilities for they are in fact a multi component assembly of various materials bounded together in a micro structure [27], [28]. It has further been shown that the rules of general engineering - that which applies to all conventional materials - fundamentally differ from those relevant to textiles engineering, where what is considered as a failure in ordinary engineering, often is the very essence of what attributes to textiles their unique and valued behaviour [29].

Away from the textile community, it is widely perceived that no one single material could ever be considered smart - only groups of materials can [23]. This observation implies that the ways in which we assemble materials into systems could potentially play a key role making them smart. And while this logic has already been applied onto electronics many years ago [23], it may also ring true with textiles today - being the materials systems that they are.

In textiles, the most common construction methodology is that of weaving. The first recorded documentation of woven textiles dates back to the Stone Age and early Bronze Age [30], [31], but historians believe that weaving travels even further, beyond the Neolithic [32]. The action of weaving itself when yarns interlace over one another at 90 degrees angle - also dates back thousands of years, preceding the invention of the wheel. The remarkable thing about weaving is that since the emergence of the technique, the basic structural architecture of weaves has changed very little and this remains the building block for most woven fabrics until this very day [33], [34], [35]. There is therefore much to said about such a resilient structuring method.

However, although the principles of weaving themselves have hardly changed throughout time, since the 18th century the development of weaving machines has considerably evolved as a direct response to the widening innovations of yarn-spinning technologies [36], [37], [38]. The fundamental driver of the Industrial Revolution was the creation of an automatic manufacture line that saved the costs of labour, increased the rates of production and eliminated much human error. However, throughout this process the geometry of weave structures have hardly changed. This strongly speaks of the merits of such construction method but also it indicates that the innovation in the process of weaving did not enhance textile construction or enabled it to develop new potentials. Rather, it was simply driven by economical and commercial considerations [16].

The new weaving machines that came out of the Industrial Revolution - and those which we still rely upon today - reveal an essential link between apparatus and textile products; connecting the specifications and hence, limitations of manufacture to the products which they produce. Special weaving looms that have been designed for the production of unique weave structure reaffirm this strong link between machine and woven structuring geometries [39], [40], [41], [42]. Surprisingly today, worldwide, woven textile production is still governed by the very same machine specifications that were developed during the Industrial Revolution - some 250 years ago.

Further to the introduction of STEM considerations to textile developments, recent decades have seen the industry witness a dramatic increase in the development of new technologies and textile components. Among many, these include High Performance fibres [43], shape memory polymer fibres and yarns [44], phase change fibre materials [45], [46], and nano-fibres [47]. Smart textile constructions and woven constructs in particular, as a result, face an unimaginable gap between advanced material science and what could only be described as ancient textiles construction methodologies. How can we therefore expect to create smart woven textiles when our component materials far exceed our methods of production?

The answer could be routed in an entirely different construction method - that to some, additive manufacturing has been guaranteeing a promise to deliver [48], [49]. However research shows that no additive manufacturing technique could compete with creating the structural integrity that textile systems offer [16]. This strongly indicates that we might have to revisit our woven construction methods as a result to widen the exploration and creation of woven smart textiles in the future. How can we therefore use weaving as a structuring method for smart textiles? What role can weaving play in the creation of smart textile structures, and more importantly - from a pedagogic perspective - where does it leave us as teachers? 


\subsection{Smart textile pedagogy}

Greek philosophers like Plato used to distinguish between 'techne' and 'episteme' as two different types of knowledge [50] - mostly in an attempt to describe the difference between tacit and explicit knowledge. The interesting thing about this is that they often used weaving as the characteristic example for 'techne' [51]. Weaving therefore, is not only one of the oldest methods for making, but it also appears to be one of the oldest methods for leaning.

Weaving falls into the framework of behaviourist learning. Behaviorism, as a strategy for accumulating knowledge, borrows it bearings from psychology and particularly from the notion that actions could be learned over and over again, particularly in the presence of reinforcement and feedback. The behaviourist explains the accumulation of knowledge as a repertoire of behaviours, where according to Skinner (1976) "knowledge is action, or at least rules for action" [52]. Behaviourism is an action based approach to learning where the learner is entirely passive and the evaluation of the task is placed with the teacher, who assesses whether things are done in a correct manner. This symbolises a hierarchical strategy for the formation of new knowledge. And through that very same framework, the weaver can be seen as a behaviourist learner.

Throughout history, weaving has been taught through methods of apprenticeship - where knowledge in its tacit form, has been acquired through observation, practice and repetition. Today, this still applies, and anywhere in the world - however rural or urban - weaving is not being taught in the classroom, but mainly in workshops. Even at the Royal College of Art - as an example for an institution who comply with modern pedagogy frameworks - weaving is being taught largely through demonstration, and not through textbooks. And this too relates very well to a behaviourist approach to learning, as well as to teaching.

As weave practitioners - and more importantly, as teachers - we are now forced to face the challenge of smart textiles through the eyes of the behaviourist learner. And the challenge is not small. As we are asked to re-think about our woven methods of production for the development of future smart textiles, we must also consider ways of disrupting the rhythm of the behaviourist approach. In other words, in the newly formed landscape of smart textile tuition, we must learn to teach weave behaviourists to mis-behave.

In A Thousand Plateaus, the term 'nomad thought' is used to describe an element within a rhizomatic approach to learning [53]. Here, a rhizome is used intellectually to disrupt the division between subject, concept, and process. According to Deleuze and Guattari (1988) the rhizomatic approach replaces restrictive analogy with a conductivity that knows no bounds - allowing freedom of thought and conception of new ideas [53]. In other words, the pedagogic rhizome can be described as anarchy itself. With regard to weaving, the idea of a nomad thought, of a thought that belongs nowhere, a homeless thought, that nonetheless is potent and reactive - could very well be the medicine that behaviourists learners require to break away from their practical constraints.

Rhizomatic analyses are already beginning to occupy the pedagogic landscape in order to challenge traditional power structures through the voicing of opinions - opening issues in a messy but authentic way [54]. According to which, the rhizomatic approach allows learners and teachers alike to see its subject matters out of context, naked and naive - enabling an intellectual culture where there are no taboos. The rhizomatic approach to learning therefore represents true freedom of creativity. A place where everything that was being held sacred before might be questioned for the sake of innovation.

Within the context of this paper, and the challenge of smart woven constructions, a rhizomatic approach to learning may just allow us to re-think, re-imagine, re-appropriate and recreate solutions creatively away from long applied methods of teaching. This intellectual space is born out of necessity to address some of the technical and intellectual issues that have been left unresolved with regard to the development of woven smart textiles. And indeed, one of the overriding challenges within such a task would be the unraveling of the behaviourist tuition.

What should be clarified at this point is that I don't wish to represent the pedagogic rhizome as a method for the unravelling of behaviours. This would be entirely counterintuitive. Nor I wish to resolve the existential tension between behaviorism and rhizomatism by crowning a deserving winner. The proposal here is for a space that exist because of that tension. An agonistic space where the battle between rule and rebel persists - where hybrid thoughts could translate into new woven solutions and 
resulting in an interesting way of equipping our students in thinking creatively and appropriately about parts of the professional problems that they face.

In response to this research, in November 2018, the Royal College of Art will be running a capsule cross disciplinary project that will challenge and test this theory. This project - open to students from all over the college, and not just textiles - will examine what happens when the behaviourist attitudes meet a rhizomatic approach to learning in order to gain new knowledge.

\section{CONCLUSIONS}

Smart textiles demands us to re-think our proven and tested methods of teaching. In some areas it requires us to simply invent a new form of tuition - one that will equip our students with an appropriate set of skills and as a result, would allow them to embed into the ever evolving market. Addressing our methods of teaching and our students' modified needs of learning is vital for the survival of innovation. This will enable the relationship between academe and the textile industry to evolve and will help fulfil the ambitions of increasing the number of young graduates suitable for employment and as a result will directly feed our intellectual debate and our national and global commercial wealth.

\section{ACKNOWLEDGEMENTS}

The original research was taken at Northumbria University with the continual financial support of the School of Design.

\section{REFERENCES}

1. L. E. Nielsen, Mechanical Properties of Polymers. Reinhold Publishing Corporation, 1963.

2. L. W. S. Hearle, Polymers and their Properties. Vol 1: Fundamentals of Structure and Mechanics. Ellis Horwood Ltd, 1982.

3. J. S. Robinson (ed.), Spinning, Extruding and Processing of Fibres. Noyes Data Corporation, 1980.

4. H. Brody (ed.), Synthetic Fibre Materials. Longman Scientific \& Technical, 1994.

5. A. Das and R. Alagirusamy, Science in Clothing Comfort. WPI Publishing, 2010.

6. L. Van Langenhove (ed.), Smart Textiles for Medicine and Healthcare. Woodhead Publishing Ltd, 2007.

7. A. R. Bunsell (ed.), Handbook of Tensile Properties of Textile and Technical Fibres. Wood-

head Publishing Ltd, 2009.

8. G. Pohl (ed.), Textiles, Polymers and Composites for Building. Woodhead Publishing Ltd, 2010.

9. S. J. Eichhorn, J. W. S. Hearle, M. Jaffe and T. Kikutani (eds.), Handbook of Textile Fibre

Structure. Vol 2: Natural, Regenerated, Inorganic and Specialist Fibres. Woodhead Publishing Ltd, 2009.

10. W. E. Morton and J. W. S. Hearle, Physical Properties of Textile Fibres. 4th edition. Woodhead Publishing Ltd, 2008.

11. M. A. Taylor, Technology of Textile Properties: An Introduction. 3rd edition. Forbes Publications Ltd, 2007.

12. A. Wilson, The Future of Smart Fabrics: Market and Technology Forecasts to 2012. Pira Inter. Ltd, 2011.

13. C. Field, Danger High Voltage! Edwardian Electric Tablecloth Uncovered, 2004: 
https://www.culture24.org.uk/history-and-heritage/art19432 (Accessed on: October 6th 2018).

14. H. Mattila, "Yarn to Fabric: Intelligent Textiles", in Textiles and fashion: Materials, design and technology (R. Sinclair, ed.), pp. 355-378. Woodhead Publishing Ltd, 2015.

15. A. R. Horrocks and S. C. Anand (eds.), Handbook of Technical Textiles. Elsevier; 2000.

16. L. Tandler, The Role of Weaving in Smart Material Systems, 2016 (Doctoral dissertation, Northumbria University): http://nrl.northumbria.ac.uk/id/eprint/31052 (Accessed October 6th 2018).

17. X. Tao (ed.), Smart Fibres, Fabrics and Clothing: Fundamentals and Applications. Elsevier; 2001.

18. M. Stoppa and A. Chiolerio, "Wearable Electronics and Smart Textiles: A Critical Review, in Sensors, 2014. 14 (7), pp.11957-11992.

19. R. Pailes-Friedman, Smart Textiles for Designers: Inventing the Future of Fabrics. Laurence King Publishing, 2016.

20. N. A. Johnson, E. J. Wood, P. E. Ingham, S. J. McNeil and I. D. McFarlane, "Wool as a Technical Fibre", in Journal of the Textile Institute. 2003. 94 (3-4), pp. 26-41.

21. G. E. Collins, "Fundamental Principles That Govern the Shrinkage of Cotton Goods by Washing", in Journal of the Textile Institute Proceedings, 1939. 30 (3), pp. 46-61.

22. M. J. Coplan, "Some Moisture Relations of Wool and Several Synthetic Fibers and Blends", in Textile Research Journal, 1953. 23 (12), pp. 897-916.

23. B. Culshaw, Smart Structures and Materials. Artech House, 1996.

24. V. K. Wadhawan, "Smart Structures and Materials: in Resonance, 2005.10 (11), pp. 27-41.

25. M. V. Gandhi and B. S. Thompson, Smart Materials and Structures. Chapman \& Hall, 1992.

26. Z. L. Wang and Z. C. Kang, Functional and Smart Materials: Structural Evolution and Structured Analysis. Springer Science, 1998.

27. X. Chen and J. W. S. Hearle, "Structural Hierarchy in Textile Materials: An Overview", in Modelling and Predicting Textile Behaviour (X. Chen, ed.), pp. 3-40. Woodhead Publishing Ltd, 2009.

28. N. Takano, Y. Uetsuji, Y. Kashiwagi and M. Zako, "Hierarchical Modelling of Textile Compo-

site Materials and Structures by the Homogenization Method", in Modelling and Simulation in Materials Science and Engineering, 1999. 7 (2), pp. 207-231.

29. J. W. S. Hearle, "Engineering Design of Textiles", in Indian Journal of Fibre and Textile Research, 2006. 31 (1), pp. 134-141.

30. P. R. Lord and M. H. Mohamed, Weaving: Conversion of Yarn to Fabric. Merrow Publishing, 1982.

31. E. J. W. Barber, Prehistoric Textiles: The Development of Cloth in the Neolithic and Bronze Ages with Special Reference to the Aegean. Princeton University Press, 1991.

32. E. Broudy, The Book of Looms: A History of the Handloom from Ancient Times to the Present. University Press of New England, 1979.

33. I. Emery, The Primary Structure of Fabrics. Thames \& Hudson, 1994.

34. M. Straub, Hand Weaving: And Cloth Design. Viking Press, 1977. 
35. W. Watson, Textile Design and Colour. 6th edition. Longmans Publishing, 1964.

36. A. Barlow, The History and Principles of Weaving: By Hand and by Power. Low, Marston, Searle, and Rivington, 1878.

37. S. D. Chapman, The Early Factory Masters. David \& Charles, 1967.

38. J. L. Mann, "The Textile Industry: Machinery for Cotton, Flax, Wool, 1760-1850", in A History of Technology: From Early Times to Fall of Ancient Empire (C. Singer, E. J. Holmyard, A. R. Hall and T. I. Williams, eds.), pp. 277-307. Oxford University Press, 1958.

39. T. Tyler, "Developments in Triaxial Woven Fabrics", in Specialist Yarn and Fabric Structures: Developments and Applications (R. H. Gong, ed.), pp. 141-163. Woodhead Publishing Ltd, 2011.

40. C. McCarty and M. McQuaid, Structure and Surface: Contemporary Japanese Textiles. The Museum of Modern Art, 1998.

41. L. W. Taylor, Design and Manufacture of 3D Nodal Structures for Advanced Textile Composites (Doctoral dissertation, University of Manchester): https://ethos.bl.uk/OrderDetails.do;jsessionid=5E45ECE227336A96EC5090DE1DB8F2E0? uin=uk.bl.ethos.595658 (Accessed October 6th 2018).

42. M. A. Islam, "3D Woven Structures and Methods of Manufacture", in Woven Textiles: Principles, Developments and Applications (K.L. Gandhi, ed.), pp. 264-313. Woodhead Publishing Ltd, 2012.

43. V. Gabara, "High Performance Fibres", in Synthetic Fibre Materials (H. Brody, ed.), pp. 239-262. Longman Scientific and Technical, 1994.

44. J. Hu, Shape Memory Polymers and Textiles. Woodhead Publishing, 2007.

45. H. R. Mattila (ed.) Intelligent Textiles and Clothing. Woodhead Publishing, 2006.

46. S. Mondal, "Phase Change Materials for Smart Textiles: An Overview", in Applied Thermal Engineering, 2008. 28 (11), pp. 1536-1550.

47. A. P. S. Sawhney, B. Condon, K. V. Singh, S. S. Pang, G. Li and D. Hui, "Modern Applications of Nanotechnology in Textiles", in Textile Research Journal, 2008. 78 (8), pp. 731-739.

48. G. A. Bingham, R. J. Hague, C. J. Tuck, A. C. Long, J. J. Crookston and M. N. Sherburn, "Rapid Manufactured Textiles", in International Journal of Computer Integrated Manufacturing, 2007. 20 (1), pp.96-105.

49. P. Delamore, 3D Printed Textiles and Personalised Clothing, 2004: http://www.academia.edu/ 917613/3D_Printed_Textiles_and_Personalised_Clothing (Accessed: 8 August, 2013).

50. R. Parry, "Episteme and Techne" in The Stanford Encyclopaedia of Philosophy (E. N. Zalta, ed.) Stanford University, 2014.

51. U. Lehmann, "Making as Knowing: Epistemology and Technique in Craft", in The Journal of Modern Craft, 2012. 5 (2), pp. 149-164.

52. B. F. Skinner, About Behaviorism, p. 152. Vintage Books, 1976.

53. G. Deleuze and F. Guattari, A Thousand Plateaus: Capitalism and Schizophrenia. Bloomsbury Publishing, 1988. 
54. J. Grellier, "Rhizomatic Mapping: Spaces for Learning in Higher Education", in Higher Education Research \& Development, 2013. 32 (1), pp. 83-95. 